\title{
Chronicles of a cardiologist in Canada's North
}

\author{
Doctor to the North: Thirty Years Treating \\ Heart Disease among the Inuit \\ John H. Burgess MD \\ McGill-Queen's University Press, 2008 \\ 168 pp \$34.95 ISBN 978-0-7735-3431-5
}

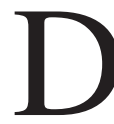
uring medical training, aspiring physicians at some point decide whether to pursue a career in academic or community medicine. Some physicians combine the 2 , by maintaining a research interest despite serving a more isolated population, or by deliberately choosing to treat an underserved population despite being located in the heart of a university. In Doctor to the North, Dr. John Burgess chronicles a career that spanned the 2 extremes of the academic/community spectrum: chief of cardiology at the Montreal General Hospital and president of the Royal College of Physicians and Surgeons of Canada on the one hand, and cardiologist to the tiny Inuit communities of the Baffin region for 25 years, on the other.

How did this happen? "When I became the director of the Division of Cardiology at MGH in 1973, spending 4 weeks of the year in the Far North treating heart disease among the Inuit was not my first priority. I therefore remember well the day that the physicianin-chief, Dr. Douglas G. Cameron, called me to his office and told me I was the consulting cardiologist to the McGill Baffin Project. There was no discussion."

Although he did not choose his role as cardiologist to the Arctic, Burgess clearly valued his travel clinics and o consultations by phone and fax with Northern health practitioners as perhaps the most rewarding aspect of his career. Although he did not remain immersed in Inuit community life for long periods of time, he witnessed profound changes in the lifestyle and health is-

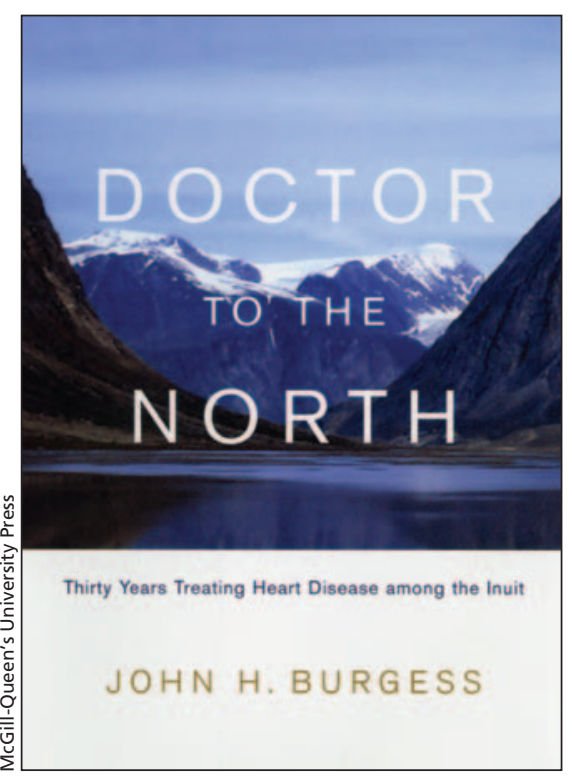

sues of his patients over 3 decades and his writing is influenced by his patients' perspectives on these changes. Far from being a distant clinical researcher, Burgess displays admiration and humility toward the patients he describes and the culture that he encountered during his northern visits.

The first third of Doctor to the North is essentially an autobiography, describing the cardiologist's training and early career written in language that is easily understood by a lay reader. Burgess' writing style is concise and uncomplicated and these chapters use frequent anecdotes to round out his portrait as a son, husband, father and interested observer of life in England, California and Canada. Although the relevance of pathology lab experience to Inuit health care is less than obvious, Burgess does link several aspects of his training to his future northern practice - from clinical training in a British "mitral clinic" to the environmental causes of rheumatic heart disease.

The middle half of the book is divided between historical content related to the Inuit and their health care and Burgess' descriptions of several patients and their particular cardiac conditions. As a clinician working in the North, I would have relished more patient descriptions and less commentary on the causes and possible solutions for current worrisome trends of obesity, unemployment and despair. However, the major categories of cardiac disease are well represented, and Burgess describes his patients with sensitivity and clinical acumen, particularly considering that only bedside examination, electrocardiography and chest radiography were available to him during travel clinics.

The final 3 chapters describe Burgess' 1984 trip to the Arctic with his beloved wife Andrea, and the final stages of Andrea's life 15 years later. $\mathrm{He}$ also describes his own experience as a patient that prompted his eventual retirement from clinical medicine. Like the rest of the book, these chapters are honestly and simply presented, with the human element in the forefront of the clinician's mind.

Burgess does not purport to be an expert in Inuit history and culture (although he obviously has researched the topic) and he is at his best when he relates his personal observations and the stories of his patients. This book offers a window into many worlds: academic medicine, northern health care, cardiology and Inuit health. I hope that it will be read and enjoyed by many who live in only one of these spheres, with no link to the others. In Doctor to the North, Burgess is a deeply human ambassador between worlds separated by culture, language, history and resources. He has left his mark on the North, but it has clearly left its mark on him as well.

\section{Amy Hendricks MDCM \\ Internal Medicine \\ Yellowknife, NWT}

